\title{
A prospective intervention study of colonoscopy reporting among patients screened or surveilled for colorectal neoplasia
}

\author{
Daphnée Beaulieu¹, Myriam Martel BSc ${ }^{1}$, Alan Barkun MD CM FRCPC MSc ${ }^{1,2}$
}

\begin{abstract}
D Beaulieu, M Martel, A Barkun. A prospective intervention study of colonoscopy reporting among patients screened or surveilled for colorectal neoplasia. Can J Gastroenterol 2012;26(10):718-722.
\end{abstract}

BACKGROUND: The impact of modifying electronic colonoscopy reporting software for improving adherence to guidelines regarding quality standards documentation remains poorly characterized.

METHODS: Consecutive colonoscopy reports of patients undergoing screening or surveillance for colorectal neoplasia were reviewed. Following a pre-intervention quality audit conducted in 2009, some modifications were made to the reporting software (Endoworks, Olympus Corporation, USA), including changes to field navigation, drop-down menus and visual cues, to optimize all compulsory items identified by existing guidelines in the report-generating template. Results from both audits were compared. Independent validation of $10 \%$ of all data was completed.

RESULTS: In 250 patient reports (mean [ \pm SD] age $61.7 \pm 10.2$ years, $51.2 \%$ female, February to May 2011) of five endoscopists (mean $11.6 \pm 7.8$ years in practice), procedural indication was always present, as was informed consent. Seventy-six per cent of patients had undergone previous colonoscopy, $41 \%$ provided a previous colonoscopy date, with details on past polyp removal in $42.9 \%$. Most procedural indicators were recorded (examination date 100\%, medications given 100\%, difficulty level $96.4 \%$, preparation quality $100 \%$ ). All reports noted extent of visualization (cecal intubation in $97.6 \%$, photo documentation in $96.8 \%$ ). Total procedural time was recorded in $8.2 \%$ and withdrawal time in $44 \%$. Polyps were reported in 112 patients (44.8\%), with polyp size $(5.01 \pm 4.42 \mathrm{~mm})$ reported in $95.5 \%$, morphology in $88.4 \%$ and anatomical location in all. The method of polyp removal was missing in $2.7 \%$ of reports. Significant improvements were noted in the documentation of withdrawal and total time, cecal landmarks, type of bowel preparation, completeness of removal, morphology and method of polyp removal, and photo documentation compared with the 2009 audit. CONCLUSION: These results illustrate the value of targeted modifications to an electronic colonoscopic reporting system in significantly enhancing the quality of reporting.

Key Words: Audit; Colonoscopy; Colorectal cancer; Endoscopy; Quality; Reporting; Surveillance

$\mathrm{T}$ he second leading cause of death from cancer in Canada is colorectal cancer (CRC), and screening of average-risk patients is highly recommended among experts (1). Colonoscopy is recognized as one of the most accurate procedures for CRC screening, diagnostic follow-up of an abnormal entry-level test, adenoma surveillance and primary screening. The effectiveness and safety of colonoscopy depends on the quality of examination. Evidence suggests that clinical quality indicators vary among centres and physicians (2).

In 2007, a Quality Assurance Task Group was formed from the National Colorectal Roundtable in the United States. This group developed reporting and data systems for colonoscopy (CO-RADS) to

\author{
Une étude d'intervention prospective des rapports \\ de coloscopie chez des patients subissant un \\ dépistage ou une surveillance de néoplasie \\ colorectale
}

HISTORIQUE : Les conséquences de la modification d'un logiciel de rapport électronique des coloscopies pour améliorer le respect des lignes directrices relativement à l'attestation des normes de qualité demeurent peu caractérisées.

MÉTHODOLOGIE : Les chercheurs ont examiné des rapports consécutifs de coloscopie chez des patients subissant un dépistage ou une surveillance de néoplasie colorectale. Par suite d'une vérification de qualité avant l'intervention menée en 2009, certaines modifications ont été apportées au logiciel de rapport (Endoworks, Olympus Corporation, États-Unis), y compris des changements à la navigation d'un champ à l'autre, aux menus déroulants et aux indices visuels, afin d'optimiser tous les éléments obligatoires déterminés par les lignes directrices en place contenus dans le modèle de production de rapport. Les chercheurs ont comparé les résultats des deux vérifications et ont vu à la validation indépendante de $10 \%$ de toutes les données.

RÉSULTATS : Dans 250 rapports de patients (d'un âge moyen [ $\pm E ́ T]$ de $61,7 \pm 10,2$ ans, $51,2 \%$ de femmes, entre février et mai 2011) provenant de cinq endoscopistes (années de pratique moyennes de 11,6 $\pm 7,8$ ans), ceux-ci précisaient toujours l'indication justifiant l'intervention, de même que le consentement éclairé. Soixante-seize pour cent des patients avaient déjà subi une coloscopie. Dans $41 \%$ des cas, une date de coloscopie antérieure était précisée, ainsi que de l'information sur l'extraction antérieure de polypes dans $42,9 \%$ des cas. La plupart des indicateurs d'intervention étaient indiqués (date d'examen $100 \%$, médicaments administrés $100 \%$, niveau de difficulté $96,4 \%$, qualité de la préparation $100 \%$ ). Tous les rapports soulignaient l'étendue de la visualisation (intubation cæcale dans $97,6 \%$ des cas, attestation par photos dans $96,8 \%$ des cas). La durée totale de l'intervention était précisée dans $8,2 \%$ des cas et la durée de l'extraction, dans $44 \%$ des cas. On avait décelé des polypes chez 112 patients $(44,8 \%)$, et on en a consigné la dimension $(5,01 \pm 4,42 \mathrm{~mm})$ dans $95,5 \%$ des cas, la morphologie dans $88,4 \%$ des cas et le foyer anatomique dans tous les cas. Le mode d'extraction des polypes était absent de 2,7\% des rapports. Par rapport à la vérification de 2009, les chercheurs ont constaté d'importantes améliorations à la consignation de l'extraction et du temps total, des repères cæcaux, du type de préparation intestinale, de l'exhaustivité de l'ablation, de la morphologie et du mode d'extraction des polypes ainsi que de l'attestation par photos.

CONCLUSIONS : Ces résultats démontrent la valeur des modifications ciblées apportées à un système de déclaration électronique des coloscopies pour améliorer considérablement la qualité des rapports.

assist endoscopists in establishing standards that permit the monitoring of quality indicators in their everyday practice. By creating a standardized reporting system, the Quality Assurance Task Group aimed to improve the quality of examination. A study using CO-RADS was conducted to uncover gaps in the colonoscopy reports (1). Comparative evidence from Canada is lacking.

Therefore, in 2009, we conducted a study to assess the level of adherence of the McGill University Health Centre (MUHC, Montreal, Quebec) endoscopy reports with the criteria set forth by the Quality Assurance Task Group of the National Colorectal Cancer Roundtable, and to determine the quality indicators exhibiting the

\footnotetext{
${ }^{1}$ Division of Gastroenterology; ${ }^{2}$ Division of Clinical Epidemiology, McGill University and McGill University Health Centre, Montreal, Quebec Correspondence: Dr Alan Barkun, Division of Gastroenterology, McGill University Health Centre, Montreal General Hospital site, 1650 Cedar Avenue,

Room D7-346, Montreal, Quebec H3G 1A4. Telephone 514-934-8309, fax 514-834-8531, e-mail alan.barkun@muhc.mcgill.ca

Received for publication October 31, 2011. Accepted January 16, 2012
} 
poorest adherence (4). As a result of that study, we have since modified the electronic reporting system to improve adherence to the proposed reporting standards.

Consequently, the primary aims of the present study were to perform a prospective intervention on MUHC colonoscopy reporting to determine the level of documentation of key quality indicators and measure improvement over time.

\section{METHODS}

Patient and endoscopist population

Consecutive colonoscopy reports from procedures performed between February and May 2011 were selected. Only procedures for screening or surveillance of patients with previous colorectal neoplasia were considered. Colonoscopy reports completed for other indications were excluded. Compared with the 2009 pre-intervention cohort, the analysis was limited to the five endoscopists who had access to the revised endoscopy reporting template.

\section{Institution and intervention in the form of modification of the} electronic reporting system template

The Montreal General Hospital site of the MUHC (MUHC-MGH) is a tertiary care institution with a four-room endoscopy unit staffed by 12 medical and surgical endoscopists. Patients can access the services of the unit both through same-day consultation and procedural pathways at the request of a referring physician, or on a subsequent date after the specialist endoscopist has initially assessed the patient in the office. On average, 11,000 procedures are performed at the MUHCMGH per year, of which 75\% were colonoscopies in 2008.

The unit is equipped with a structured, computerized endoscopic report generator enabling image and video capture (Endoworks, Olympus Corporation, USA). It is used for all cases performed during and outside regular hours by all endoscopists. The data file from the report is electronically transmitted to a central data repository housed at the MUHC-MGH. The information is then securely locked in the Endoworks database.

The routine colonoscopy report template includes some compulsory fields, default population of certain fields included in the final report for which the endoscopist needs to approve or choose alternatives, drop down menus for selecting other components of the report and free text entry. Following the pre-intervention quality audit, some modifications were made to improve field navigation, drop-down menus and visual cues in 2009 in the absence of compulsory field entries that cannot be added due to restrictions in the software. Adjustments were also made so that the report-generating template would contain all of the variables present in the standardized colonoscopy report established by the Quality Assurance Task Group of the National Colorectal Cancer Roundtable. Participating endoscopists were aware that this prospective intervention study was being peformed at the time the reports were entered in Endoworks. Any post hoc amendment of a report can be identified through a review of the electronic log entries because the initial report is digitally signed and locked.

To also report on the adenoma and cancer detection rates, the pathology results from an institutional electronic medical file software (OACIS), which is not part of Endoworks, were accessed because current practice has yet to directly link the pathology results to the actual endoscopy report.

A group meeting was conducted to stimulate the adoption of the new template in the reporting system. During the intervention period, two e-mail reminders were also sent to the team.

\section{Quality indicators}

Based on continuous quality improvement indicators established by the Quality Assurance Task Group of the National Colorectal Cancer Roundtable (1), a specific list of quality indicators that should be explicitly addressed in the colonoscopy reports was developed (Table 1) and made available to the referring physician; these have been adopted as part of a province-wide CRC screening pilot project (www.msss.gouv.qc.ca/sujets/santepub/pqdccr/index. php). Unplanned interventions for adverse events included only those interventions that were reported at the time of colonoscopy because no specific mechanism or manpower support currently exist at the MUHC-MGH digestive endoscopy unit to allow for the reliable and complete capture of downstream adverse events following discharge home.

\section{Data collection}

The current study was a retrospective review of all consecutive eligible reports using a standardized checklist developed using the Quality Assurance Task Group of the National Colorectal Cancer Roundtable publication (1). Withdrawal times were measured by the endoscopist using a wall-mounted clock. Although the identification of cases was performed through the search function of the electronic reporting software, data extraction was based on a review of the final report and not through field searches of the software's search tool. Screened patients were dichotomized into those for whom the indication for colonoscopy was average or increased risk. Individuals with a family or personal history of CRC or polyps were categorized as increased-risk patients. Data were compiled and individually analyzed by a trained research assistant using a specially developed electronic data abstraction form. Using a standardized glossary of study variables, $10 \%$ of all entered data were reviewed by an independent observer and validated.

\section{Sample size calculation and statistical analysis}

The sample size was based on a preliminary analysis of the first 111 consecutive reports. The widest point estimate for the presence (or absence) of documentation of a quality indicator was for that of polyp removal (51.1\% [95\% CI 35.9\% to 63.3\%). The number of reviewed reports needed to narrow this range to $10 \%$ (assuming an identical projected point estimate of $51 \%$ [95\% CI $45.5 \%$ to $55.8 \%$ ]) was estimated to be 250 . Therefore, the audit was completed up to this consecutive number of patients.

Descriptive variables are presented as means and SDs for continuous variables, and proportions and 95\% CIs for categorical variables. Inferential testing was performed using the Student's $t$ test for continuous variables and the $\chi^{2}$ test for categorical variables. Multivariable analyses were performed using logistic regression, and the best fitting model was selected according to goodness-of-fit indexes. All analyses were performed using SAS version 9.1 (SAS Institute Inc, USA).

\section{RESULTS}

From February 1 to May 31, 2011, 250 reports on 250 consecutive patients were collected using the following variables: patient demographics and history, procedure indications, technical description, colonoscopy findings, interventions, unplanned events, follow-up plan and pathology. All procedures were performed during that time frame and only screening-related colonoscopies were considered. The five participating endoscopists had a mean of $11.6 \pm 7.8$ years of pratice experience. All variables that appeared in $100 \%$ of reports involved direct generation by the software, except for documentation of discharge plans.

\section{Patient demographics and endoscopists' description}

The mean age of the patient population was $61.7 \pm 10.2$ years, with $51.2 \%$ of the patients being women. The procedure indication pertaining to the risk of the patient was indicated in every report. Overall, $48.8 \%$ of examinations were performed on average-risk individuals, $23.1 \%$ of patients had a personal history of previous colonic polyp or cancer, and $32.1 \%$ of patients had first-degree relatives with CRC or adenomas (Table 2).

\section{Preprocedure indicators}

The American Society of Anesthesiology classification field was completed in $96.4 \%$ of the reports. The documentation of informed consent was noted in all reports. Overall, $76 \%$ of patients had undergone a previous colonoscopy, the date of the previous examination was 
TABLE 1

\section{Colonoscopy quality indicators}

\begin{tabular}{|c|}
\hline Patient demographics and history \\
\hline Age \\
\hline Sex \\
\hline Medical record number \\
\hline Management plans \\
\hline Informed consent documentation \\
\hline Previous gastrointestinal procedures: Documented date (yes/no) \\
\hline Documentation of American Society of Anesthesiologists classification \\
\hline Indications for procedure \\
\hline Average risk \\
\hline Increased risk \\
\hline Incomplete colonoscopy \\
\hline Postadenoma resection \\
\hline Procedure: Technical description \\
\hline Date and time \\
\hline Sedation \\
\hline Level of difficulty of the procedure \\
\hline Bowel preparation \\
\hline Type \\
\hline Quality \\
\hline Actual extent of examination \\
\hline Cecal intubation (yes/no) \\
\hline Documentation of cecal landmarks \\
\hline Appendiceal orifice \\
\hline Ileocecal valve \\
\hline Total time recorded (yes/no) \\
\hline Withdrawal time recorded (yes/no) \\
\hline Colonoscopic findings \\
\hline Colonic polyp(s): \\
\hline Number \\
\hline Size \\
\hline Morphology \\
\hline Anatomical location \\
\hline Method of removal \\
\hline Completeness of removal (yes/no) \\
\hline Retrieved (yes/no) \\
\hline Sent to pathology (yes/no) \\
\hline Interventions/unplanned events \\
\hline Unplanned interventions and complications \\
\hline $\begin{array}{l}\text { Documentation of discharge plans (information to patient, information to } \\
\text { referring physician) }\end{array}$ \\
\hline Pathology \\
\hline Documentation of pathology results to the patient and the physician \\
\hline Adenoma detection (yes/no) \\
\hline Cancer detection (yes/no) \\
\hline
\end{tabular}

noted in $41 \%$ of reports and details about previous polyp resection were noted in $42.9 \%$. As a result, in $57.1 \%$ of cases, the colonoscopy report lacked sufficient information to determine whether the surveillance interval adhered to published guidelines (Table 3).

\section{Procedural indicators}

The date of the examination was recorded in all reports. Administered medications and dosage were indicated in all of the reports, while the level of difficulty of the procedure was reported in $96.4 \%$. The quality of the bowel preparation was always recorded, while the preparation type was recorded in only one-half. When present, preparation quality was described as excellent in $30.7 \%$, good in $59.8 \%$, fair in $7.1 \%$ and poor in $2.5 \%$. All reports included information about cecal intubation. The cecum was reached in $97.6 \%$ of examinations, while cecal landmarks (appendiceal orifice and/or ileocecal valve) were
TABLE 2

Patient population and endoscopists description

\begin{tabular}{|c|c|c|}
\hline & \multicolumn{2}{|c|}{ Cohort } \\
\hline & $\begin{array}{c}2009 * \\
(n=130)\end{array}$ & $\begin{array}{c}2011^{*} \\
(n=250)\end{array}$ \\
\hline Age, years, mean $\pm S D$ & $62.8 \pm 10.2$ & $61.7 \pm 10.2$ \\
\hline Sex documented & $130(100)$ & $250(100)$ \\
\hline \multicolumn{3}{|l|}{ Procedure indications documented } \\
\hline Average risk & $49(40.8)$ & $119(48.8)$ \\
\hline Personal history & $37(32.7)$ & $56(23.1)$ \\
\hline Family history & $35(31.0)$ & $78(32.1)$ \\
\hline HNPCC & $1(0.9)$ & $0(0)$ \\
\hline Familial adenomatous polyposis & $2(1.8)$ & $0(0)$ \\
\hline \multicolumn{3}{|l|}{ Endoscopist specialty } \\
\hline Gastrointestinal & $5(100)$ & $5(100)$ \\
\hline Endoscopist's practice, years, mean \pm SD & $10.6 \pm 7.8$ & $11.6 \pm 7.8$ \\
\hline
\end{tabular}

Data presented as $n$ (\%) unless otherwise indicated. *Endoscopists, $n=5$. HNPCC Hereditary nonpolyposis colorectal cancer syndrome

TABLE 3

Preprocedural indicators

\begin{tabular}{lccr}
\hline & \multicolumn{2}{c}{ Cohort, $\mathbf{n}(\%)$} & \\
\cline { 2 - 3 } & $\mathbf{2 0 0 9}$ & $\mathbf{2 0 1 1}$ & \\
Quality indicator sought in the report & $(\mathbf{n = 1 3 0 )}$ & $(\mathbf{n = 2 5 0 )}$ & $\mathbf{P}$ \\
\hline Consent documentation & $130(100)$ & $250(100)$ & \\
Management plan for anticoagulation & $1(1.3)$ & $0(0)$ & 0.0767 \\
Previous GI colonoscopy documented & $92(70.8)$ & $190(76)$ & 0.2688 \\
Previous GI colonoscopy date documented & $18(20)$ & $34(41)$ & 0.0027 \\
ASA classification documented & $0(0)$ & $241(96.4)$ & $<0.0001$ \\
Adenoma surveillance documented & $14(15.2)$ & $7(3.7)$ & 0.0005 \\
Details available & $4(28.6)$ & $3(42.9)$ & 0.0355 \\
\hline
\end{tabular}

ASA American Society of Anesthesiologists; GI Gastrointestinal

noted in $95.2 \%$ when the cecum was reached. Photo documentation was present in $96.8 \%$ of the reports. Retroflexion in the rectum was performed in $99.1 \%$ of the procedures. Total time of the procedure was recorded in $8.2 \%$ of reports, whereas the withdrawal time was recorded in $44 \%$ of cases. Intraprocedural complications were noted in $4.8 \%$ (Table 4$)$.

Colonoscopic findings

Polyps were found in 112 patients (44.8\%). Overall, the polyp size was recorded in $95.5 \%$, and polyp morphology in $88.4 \%$ of reported polyps. The mean polyp size was $5.01 \pm 4.42 \mathrm{~mm}$. The anatomical location of the polyps were always documented. The method of polyp removal was recorded in $97.3 \%$ of the reports. When specified, $42.3 \%$ of the polyps were removed by cold biopsy, $12.6 \%$ by cold snare and $39.6 \%$ by snare cautery (Table 5). Post procedural indicators are listed in Table 6. A full $98.2 \%$ of all polyps were retrieved and $97 \%$ were sent to pathology. Of all retrieved polyps, $32 \%$ were adenomas, $4 \%$ were advanced adenomas and none were cancerous (Table 7).

Postprocedural indicators

Documentation of discharge plans was always included in the reports. No postdischarge precautions to the patient were documented in the electronic template. In addition, no link yet exists between this template and the institutional electronic medical record for pathology results; therefore, no documentation from pathology was included in the endoscopy reports.

Pre- versus postintervention comparisons

Tables 2 to 7 compare the 2009 and 2011 cohorts with regard to all quality indicators and outcome variables. 
TABLE 4

\section{Procedural indicators}

\begin{tabular}{lccc}
\hline & \multicolumn{2}{c}{ Cohort, $\mathbf{n}(\%)$} & \\
\cline { 2 - 3 } & $\mathbf{2 0 0 9}$ & $\mathbf{2 0 1 1}$ & \\
Quality indicator sought in the report & $\mathbf{( n = 1 3 0 )}$ & $\mathbf{( n = 2 5 0 )}$ & $\mathbf{P}$ \\
\hline Date of examination documented & $130(100)$ & $250(100)$ & - \\
Medications with dosage documented & $129(99.2)$ & $250(100)$ & 0.1650 \\
Level of difficulty documented & $129(99.2)$ & $241(96.4)$ & 0.1020 \\
Bowel prep quality documented & $130(100)$ & $250(100)$ & - \\
Bowel prep type documented & $0(0)$ & $125(50)$ & $<0.0001$ \\
Actual extent of examination documented & $130(100)$ & $250(100)$ & \\
Cecal intubation documented & $123(94.6)$ & $244(97.6)$ & 0.1289 \\
Photo documentation & $115(88.5)$ & $242(96.8)$ & 0.0012 \\
Documentation of cecal landmarks & & & \\
$\quad$ Appendical orifice & $105(80.8)$ & $237(94.8)$ & $<0.0001$ \\
$\quad$ Ileocecal valve & $46(35.4)$ & $179(71.6)$ & $<0.0001$ \\
Retroflexion in rectum documented & $127(97.7)$ & $209(99.1)$ & 0.3103 \\
$\quad$ Withdrawal time recorded & $0(0)$ & $107(44)$ & $<0.0001$ \\
Total time recorded & $0(0)$ & $20(8.2)$ & 0.0008 \\
Intraprocedural complications documented & $0(0)$ & $12(4.8)$ & - \\
\hline
\end{tabular}

prep Preparation

TABLE 5

Colonoscopic findings: Polyps

\begin{tabular}{|c|c|c|c|}
\hline \multirow[b]{2}{*}{$\begin{array}{l}\text { Quality indicator sought in the } \\
\text { report }\end{array}$} & \multicolumn{2}{|c|}{ Cohort, n (\%) } & \multirow[b]{2}{*}{$\mathbf{P}$} \\
\hline & $\begin{array}{c}2009 \\
(n=130)\end{array}$ & $\begin{array}{c}2011 \\
(n=250)\end{array}$ & \\
\hline Polyp findings documented & $71(54.6)$ & $112(44.8)$ & 0.1262 \\
\hline Polyp size documented & $55(77.5)$ & 107 (95.5) & $<0.0001$ \\
\hline Morphology documented & $41(57.7)$ & $99(88.4)$ & $<0.0001$ \\
\hline Anatomical location documented & 70 (98.6) & $112(100)$ & 0.2079 \\
\hline Method of removal documented & $48(67.6)$ & $109(97.3)$ & $<0.0001$ \\
\hline Polyp retrieval documented & $50(89.3)$ & $110(98.2)$ & 0.0104 \\
\hline $\begin{array}{l}\text { Documentation that the polyp was } \\
\text { sent to pathology }\end{array}$ & $50(89.3)$ & $97(86.6)$ & 0.0474 \\
\hline
\end{tabular}

\section{DISCUSSION}

Modifications to the electronic reporting system, in the form of improved field navigation, drop-down menus and visual cues in the absence of compulsory field entries, were made so that it would contain all of the variables present in the Standardized Colonoscopy Report established by the Quality Assurance Task Group of the National Colorectal Cancer Roundtable. The final version of the Standardized Colonoscopy Report includes important elements that can be measured in diverse clinical practice settings. Patient demographics and history, assessment of patient risk and comorbidities, procedure indications, procedure technical description, colonoscopy findings, assessment, interventions and unplanned events, follow-up plan and pathology are the key quality indicators that should be included in each and every colonoscopy report (1).

A number of variables were recorded in almost every colonoscopy report in both 2009 and 2011. These indicators included the date of the examination, medications with dosage, the level of difficulty of the procedure and the bowel preparation quality.

The current prospective study revealed that even with important modifications to the reporting system, some key quality fields were still lacking. Several of these fields, including withdrawal time, are important in determining the quality of the examination. For example, in the 2009 cohort, withdrawal time was never recorded. Although some improvements were noted over the ensuing two years, information in the 2011 cohort is still lacking in $56 \%$ of reports with regard to this variable. Although controversial, there is evidence that time spent during withdrawal of the colonoscope is closely correlated with rates of
TABLE 6

Postprocedural indicators

\begin{tabular}{lcc}
\hline & \multicolumn{2}{c}{ Cohort, $\mathbf{n}(\mathbf{\%})$} \\
\cline { 2 - 3 } Quality indicator sought in the report & $\mathbf{2 0 0 9}$ & $\mathbf{2 0 1 1}$ \\
\hline Documentation of discharge plans & $130(100)$ & $250(100)$ \\
Postdischarge precautions to patient & $0(0)$ & $0(0)$ \\
Documentation of pathology & $0(0)$ & $0(0)$ \\
\hline
\end{tabular}

TABLE 7

Outcomes

\begin{tabular}{lrrr}
\hline & \multicolumn{3}{c}{ Cohort, \% } \\
\cline { 2 - 3 } & $\mathbf{2 0 0 9}$ & $\mathbf{2 0 1 1}$ & P \\
\hline Polyp detection rate & 54.6 & 44.8 & 0.1262 \\
Adenoma detection rate & 36.9 & 32 & 0.3354 \\
Advanced adenoma detection rate & 7.7 & 4 & 0.1262 \\
Cancer detection rate & 0.8 & 0 & 0.1650 \\
\hline
\end{tabular}

adenoma and polyp detection. Therefore, it is an important quality indicator that should not be omitted in current-day quality audits (2).

Another important key point that may still be lacking in the 2011 cohort is detailed information about intra- and postprocedural complications. This includes events occurring during colonoscopy and after the procedure is completed. The Quality Assurance Task Group recommends that, if an event occurs that requires an unplanned intervention, it should be recorded in the endoscopy report. In both the 2009 and 2011 cohorts, although the validity of entered data is difficult to capture, the frequency of data reporting for this information appears low compared with what is cited in the literature and probably reflects inadequate documentation in the endoscopy report. This information may have been documented in a separate clinical progress sheet form, with its access being variable. Furthermore, other fields, such as the level of sedation of the patient and the type of instrument used for the colonoscopy, appear to be lacking; hence, no improvement was observed. Again, these are documented elsewhere, in this case, in the nursing notes. Neverthetheless, improvement must be sought with regard to recording of these variables because the recommendations are that this information be included in the actual endoscopy report (1).

On the other hand, there has been significant improvement in the frequency of reporting of many key quality indicators compared with what was noted in the 2009 cohort. Such variables include documentation of cecal landmarks: appendiceal orifice $(94.8 \%$ versus $80.8 \%$ $[\mathrm{P}<0.001])$ and ileocecal valve $(71.6 \%$ versus $35.4 \%[\mathrm{P}<0.001])$. Photo documentation was also increased (96.8\% versus $88.5 \%)$.

The rate of reporting of key polyp descriptors, including morphology $(88.4 \%$ versus $57.7 \%[\mathrm{P}<0.001])$, also significantly increased from 2009 to 2011. This information can impact the choice of subsequent surveillance colonoscopy intervals, and becomes a critical driver of appropriate resource utilization as part of a population-based screening program (3). Additional descriptors have also been more frequently reported, including the specified method of polyp removal $(97.3 \%$ versus $67.6 \%[\mathrm{P}<0.001])$, the completeness of polyp removal $(96.4 \%$ versus $45.1 \%[\mathrm{P}<0.001])$ and the documentation of polyps being sent to pathology ( $97 \%$ versus $89.3 \%$ ).

Some information such as American Society of Anesthesiology classification, bowel preparation type, total and withdrawal time were never recorded in the 2009 reports and now routinely appear in 2011, following the aforementioned software modifications.

Interestingly, the polyp (44.8\%) and adenoma detection rates $(32 \%)$ have not varied significantly between both cohorts and remain within the expected rates reported in the literature, especially when considering that $76 \%$ of patients in the 2011 cohort had previously undergone a colonoscopy. 
As mentioned, the identification of cases was performed through the search function of the electronic reporting software, yet data extraction was based on a review of the final report and not through field searches of the software's search tool. It is evident, however, that for a large volume audit, appropriate field choice entry - as opposed to free text completion - must be favoured by users.

Future plans to further ameliorate data reporting are being coordinated with a pilot project that is part of the Quebec Colorectal Cancer Screening program (the Programme de dépistage du cancer colorectal) implementation. Key additional intervention components include additional user-driven modifications of the reporting template, formal education sessions on using the software and planned repeat auditing. We are investigating the possibility of implementing mandatory fields; however, technical issues need to be addressed with the existing software in relation to this issue.

\section{CONCLUSION}

The prevalence of colon cancer is still a major concern in Canada. The above results clearly show that an electronic reporting system, with its inherent limitations of software developed solely for clinical reporting purposes, is a valuable tool to facilitate the monitoring of quality within a practice by increasing the frequency of recording of critical information, thus providing a tool for quality improvement, and both quality and safety indicator auditing.
ACKOWLEDEGEMENTS: The authors acknowledge the participation of members of the Divisions of Gastroenterology and Colorectal Surgery, McGill University Health Centre in the preparation of this article.

DISCLOSURES: Dr Barkun is a Research Scholar (Chercheur National) of the Fonds de la Recherche en Santé du Québec.

\section{REFERENCES}

1. Lieberman D, Nadel M, Smith RA, et al. Standardized colonoscopy reporting and data system: Report of the Quality Assurance Task Group of the National Colorectal Cancer Roundtable. Gastrointest Endosc 2007;65:757-66

2. Rex DK, Bond JH, Winawer S, et al. Quality in the technical performance of colonoscopy and the continuous quality improvement process for colonoscopy: Recommendations of the U.S. Multi-Society Task Force on Colorectal Cancer. Am J Gastroenterol 2002;97:1296-308.

3. Rex DK, Petrini JL, Baron TH, et al. Quality indicators for colonoscopy. Gastrointest Endosc 2006;63(4 Suppl):S16-28.

4. Beaulieu D, Barkun A, Martel M. A quality audit of colonoscopy reports amongst patients screened for colorectal neoplasia (CRN). Can J of Gastroenterol 2010;24 (Suppl A):A62 (Abst). 


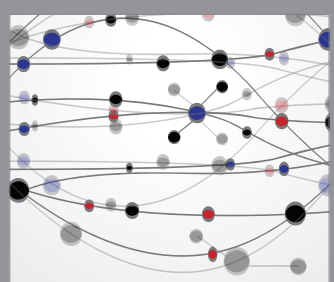

The Scientific World Journal
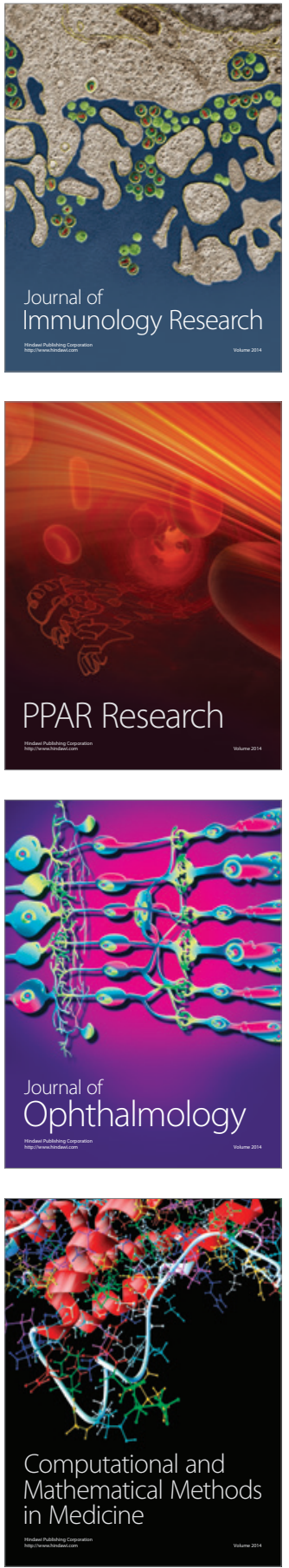

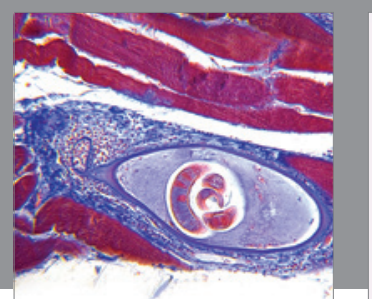

Gastroenterology Research and Practice

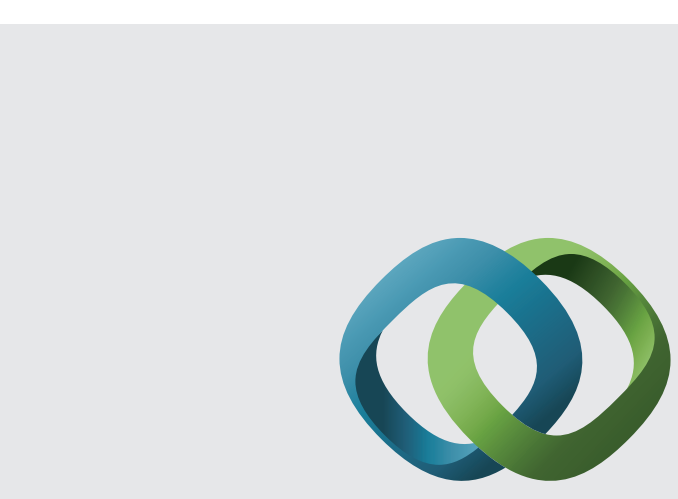

\section{Hindawi}

Submit your manuscripts at

http://www.hindawi.com
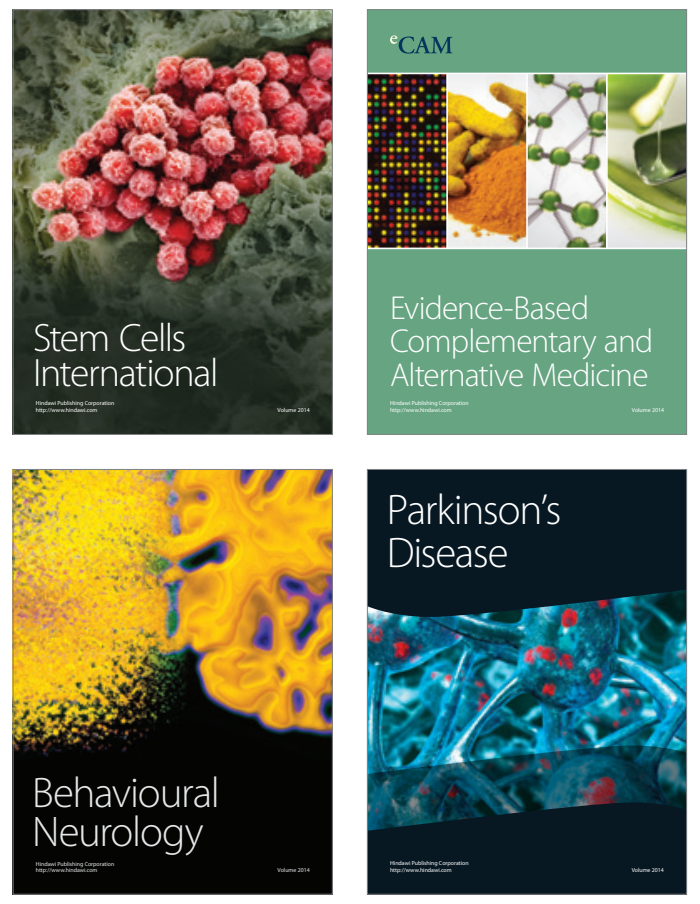
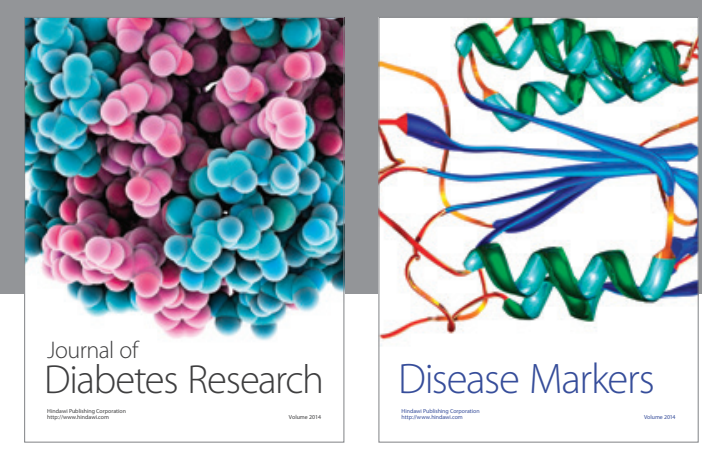

Disease Markers
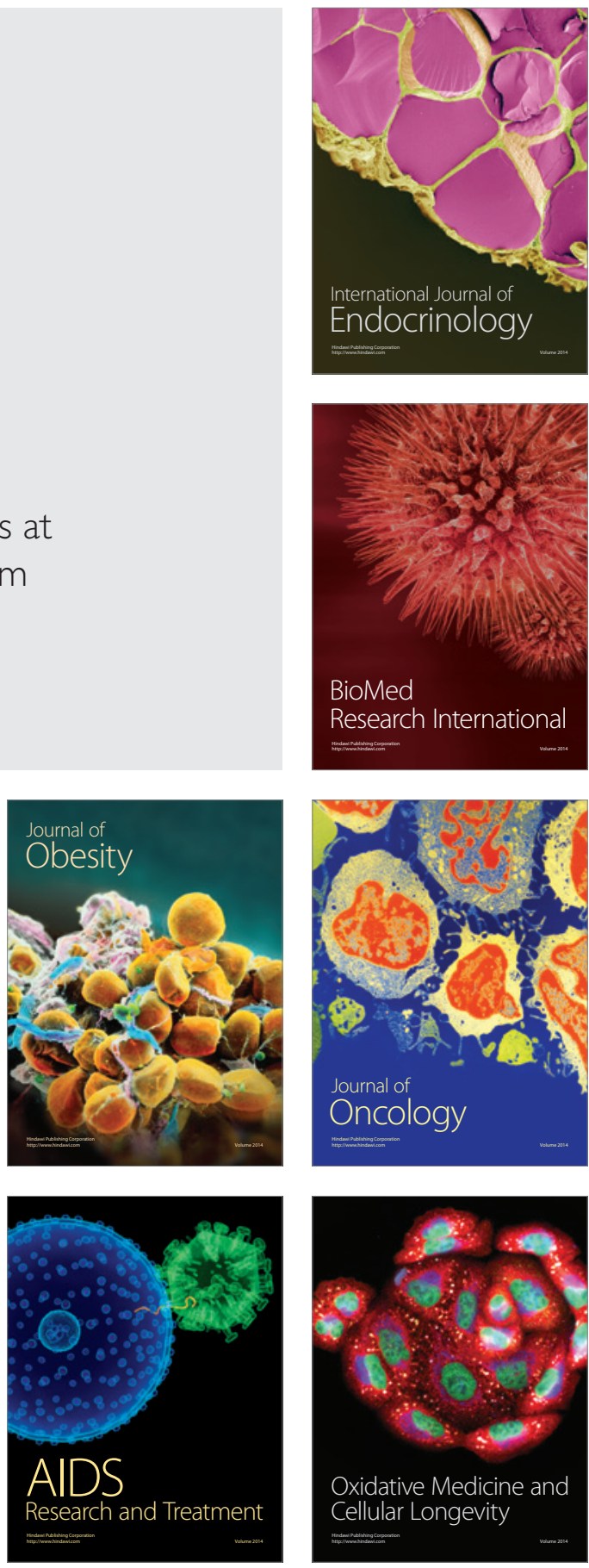